\title{
Geologia, petrografia e geoquímica da fácies granodiorítica de Novo Encanto e suas relações com o Batólito Granítico de Banabuiú (Domínio Ceará Central, Província Borborema)
}

\author{
Fábio André Craveiro MARTINS ${ }^{1,3}$, Martha Noélia LIMA², Maria do Rosário AZEVEDO², \\ Beatriz VALLE AGUADO ${ }^{2}$ José de Araújo NOGUEIRA NETO²

\begin{abstract}
Programa de Pós-Graduação em Geologia, Departamento de Geologia, Universidade Federal do Ceará Campus Universitário do Pici, Bloco 912, CEP 60455-760, Fortaleza, CE, Brasil (fabioamartins@ua.pt). Rua Mucuri s/n Área 03 - Setor Conde dos Arcos, CEP 74.968-755, Aparecida de Goiânia, GO, Brasil (marthageolima@yahoo.com.br, nogueiraneto.josedearaujo@gmail.com).

${ }^{3}$ GeoBioTec, Departamento de Geociências, Universidade de Aveiro. 3810-193, Aveiro, Portugal
\end{abstract} \\ 2 Instituto de Ciências e Tecnologia, Universidade Federal de Goiás, Campus Aparecida de Goiânia. \\ (mazevedo@ua.pt,baguado@ua.pt).
}

\begin{abstract}
Resumo. O presente trabalho tem como principal objetivo a caraterização geológica da fácies Novo Encanto e a relação petrogenética com a fácies dominante do Batólito de Banabuiú, um granito leucocrático e de duas micas. Com base nos dados de campo e dados petrográficos, a fácies Novo Encanto classifica-se com um granodiorito biotítico, cujo plagioclásio é mais cálcico (Oligoclásio= An28) e o conteúdo em minerais acessórios é superior, relativamente à fácies granítica do Batólito de Banabuiú. Os dados de geoquímica de elementos maiores confirmam a composição granodiorítica e evidenciam um caráter fracamente peraluminoso para esta fácies. A análise dos diagramas de variação química de elementos maiores e traço indica que o granodiorito corresponde a um magma híbrido, resultante da mistura entre magmas félsicos crustais e líquidos mais máficos de origem mantélica ou infracrustal. A pesquisa realizada revela que durante as fases finais da Orogenia Brasiliana, os magmas graníticos gerados por fusão parcial de materiais da crusta superior interagiram com pequenos volumes de magmas máficos de proveniência mantélica ou infracrustal, dando origem a rochas ígneas híbridas.
\end{abstract}

Palavras-chave. Orogenia Brasiliana, mistura de magmas, hibridização.

\begin{abstract}
GeOLOgY, PETROGRAPHY AND GEOCHEMISTRY OF THE NOVO ENCANTO GRANODIORITIC FACIES AND RELATIONSHIPS WITH THE BANABUIÚ GRANITE BATHOLITH (CEARÁ CENTRAL DOMAIN, Borborema Province. The main objective goal of this research is to characterize the Novo Encanto facies and to understand the relationship with dominant facies of the Banabuiú Batholith, the leucocratic two-mica granite. Based on field and petrographic datumevidence, the Novo Encanto facies is classified as a biotiteic granodiorite, whose plagioclase is more calcic (Oligoclase $=$ An28) and the accessory mineral content is higher than that observed in granitic facies of the Banabuiú Batholith. The major element geochemical data confirms the granodioritic composition and show a weakly peraluminous signature for the Novo Encanto facies. The analysis of major and trace elements variation diagrams shows that granodiorite corresponds to an hybrid rock, produced by mixing between crustal melts and mafic magmas of mantle or lower crustal origin. The present investigation reveals that the magmas generated by partial melting of upper crust interacted with small amounts of mafic magmas of mantle or infracrustal provenance at the final stages of Brasiliano Orogeny.
\end{abstract}

Keywords. Brasiliano Orogeny, magma mixing, hybridization. 


\section{Introdução}

A região de Banabuiú localiza-se no centro do Estado do Ceará e integra-se, do ponto de vista geológico, no setor setentrional da Província Borborema (Brito Neves et al., 2000), um dos cinturões orogênicos formados durante o evento Brasiliano, como consequência da colisão entre os crátons São Luís-Oeste Africano e São Francisco-Congo-Kasai no final do Neoproterozoico (Almeida et al., 1977, 1981; Brito Neves \& Cordani, 1991; Van Schmus et al., 1995). Durante a colisão Brasiliana, os terrenos que compõem o embasamento da Província Borborema foram afetados por deformação e metamorfismo regional de intensidade variável e intrudidos por abundantes volumes de magmas graníticos (Almeida et al., 1981; Ferreira et al., 1998). O Batólito Granítico de Banabuiú corresponde a uma das numerosas intrusões graníticas sin-tectônicas que se instalaram na Província Borborema nas fases finais da Orogenia Brasiliana (Lima et al., 2010).

O batólito é composto por um granito de duas micas de grão médio a fino, cujas características petrográficas, geoquímicas e isotópicas foram descritas em detalhe em trabalhos anteriores (e.g. Lima et al., 2010; Lima, 2014). Próximo da localidade de Novo Encanto, o granito de duas micas de Banabuiú contata com um pequeno corpo de granodiorito biotítico de grão fino (fácies Novo Encanto), não referido em investigações prévias. Embora com caráter muito localizado, a ocorrência desta fácies merece particular atenção pois as suas relações de contato com o granito hospedeiro sugerem o envolvimento de processos de mistura homogênia e heterogênea (mixing / mingling) entre os dois tipos de magmas.

O presente trabalho teve como principal objetivo obter dados de campo, petrográficos e geoquímicos sobre a fácies de Novo Encanto e o granito de duas micas de Banabuiú de modo a avaliar o eventual papel dos processos de mistura de magmas na sua petrogênese e a contribuição de fontes crustais e mantélicas para o plutonismo da região de Banabuiú.

\section{2 Área, materiais e métodos}

\section{1 Contexto geológico}

De acordo com Arthaud (2007) e Arthaud et al. (2015), a área estudada faz parte no Domínio Ceará Central (DCC) (Fig. 1). O embasamento da região é composto por paragnaisses e ortognaisses intensamente migmatizados que, no seu conjunto, constituem o denominado Complexo Gnáissico-Migmatítico (CGM). O CGM é limitado a este pela Zona de Cisalhamento de Orós (ZCO) e intruído a oeste pelo batólito granítico de Banabuiú (Fig. 2). Quer a encaixante migmatítica, quer o granito de Banabuiú, são cortados por numerosos filões de pegmatitos tardios, com espessura e extensão variáveis, que representam um importante recurso econômico da região (Lima et al., 2009).

Os trabalhos realizados por Lima (2014) e Martins (2014) mostram que o CGM foi afetado por três fases de deformação durante a Orogenia Brasiliana $\left(D_{1}, D_{2}, D_{3}\right)$. A última fase de deformação $\left(D_{3}\right)$ está intimamente relacionada com a atuação da zona de cisalhamento esquerda de Orós, de direção N-S, que é responsável pelo dobramento das anisotropias prévias e pelo desenvolvimento de uma foliação $S_{3}$ muito penetrativa. Durante a tectônica transcorrente associada à $\mathrm{D}_{3^{\prime}}$ as rochas do CGM atingiram as condições de pico metamórfico, na transição da fácies anfibolítica para a fácies granulítica, e sofreram fusão parcial. Apesar das rochas do CGM apresentarem microestruturas indicativas de terem sido envolvidas nos processos fusão parcial, as evidências de campo e de petrografia sugerem que a maior parte dos leucossomas presentemente alojados nestes terrenos não estão in-situ e derivaram da injecção de fundidos anatéticos gerados em níveis algo mais profundos (Lima, 2014; Martins, 2014). O CGM parece corresponder, assim, a um segmento crustal onde se acumularam grandes quantidades de fundidos anatéticos.

Admite-se ainda que a intrusão de pequenos corpos irregulares de diatexitos e do granito de duas micas de Banabuiú terá ocorrido numa etapa um pouco mais tardia, marcando 


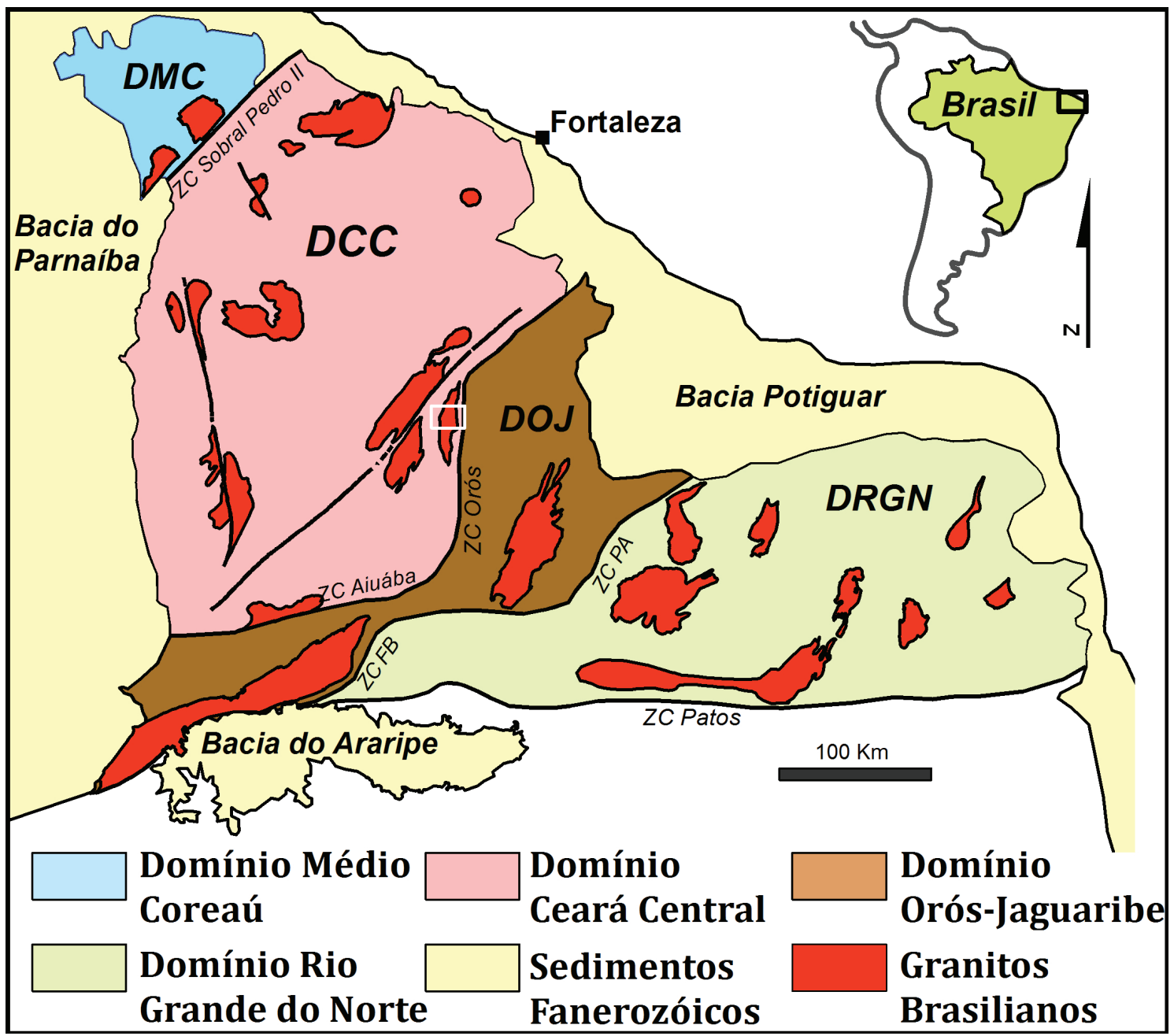

Figura 1. Mapa geológico simplificado do setor setentrional da Província Borborema e respetivos domínios geotectônicos. É no Domínio Ceará Central que está localizado o Batólito de Banabuiú (polígno branco) (modificado de CPRM-SBG, 2003 e Arthaud et al., 2015). DMC: Domínio Médio Coreaú; DCC: Domínio Ceará Central; DOJ: Domínio Orós-Jaguaribe; DRGN: Domínio Rio Grande do Norte.

Figure 1. Geological Map of the northern portion of the Borborema Province and their geotectonic domains. The Banabuiú Batholith (white polygon) is located in the Ceará Central Domain (modified from CPRM-SBG, 2003 and Arthaud et al., 2015). DMC: Médio Coreaú Domain; DCC: Ceará Central Domain; DOJ: Orós-Jaguaribe Domain; DRGN: Rio Grande do Norte Domain.

os estádios terminais do episódio transcorrente $\mathrm{D}_{3}$. Com efeito, o batólito granítico de Banabuiú constitui uma intrusão alongada na direcção $\mathrm{N}-\mathrm{S}$, concordante com as estruturas $\mathrm{D}_{3}$ e não mostra indícios de deformação no estado sólido tanto à escala mesoscópica como microscópica, o que aponta para uma instalação sin- a tardicinemática com este evento de deformação. A idade U-Pb determinada por TIMS em fracções de zircão permitiu estimar a sua idade de cristalização em 578,6 — 6,5 Ma (Lima et al., 2010; Lima, 2014), fornecendo constringimentos temporais para a última fase do ciclo orogénico Brasiliano no sector estudado.

\subsection{Materiais e métodos}

Para este estudo foram coletadas 16 amostras representativas do granito de duas micas de Banabuiú e duas do granodiorito biotítico de Novo Encanto. Procedeu-se em seguida à descrição petrográfica de todas as amostras coletadas, com base em secções polidas confecionadas para o efeito. Após trituração no moinho de mandíbulas, pulverização em moinho de ágata, quarteamento e homogeneização, as amostras foram enviadas para o laboratório comercial Activation Laboratories - Actlabs (Ontário, Canadá), onde se realizaram as análises 


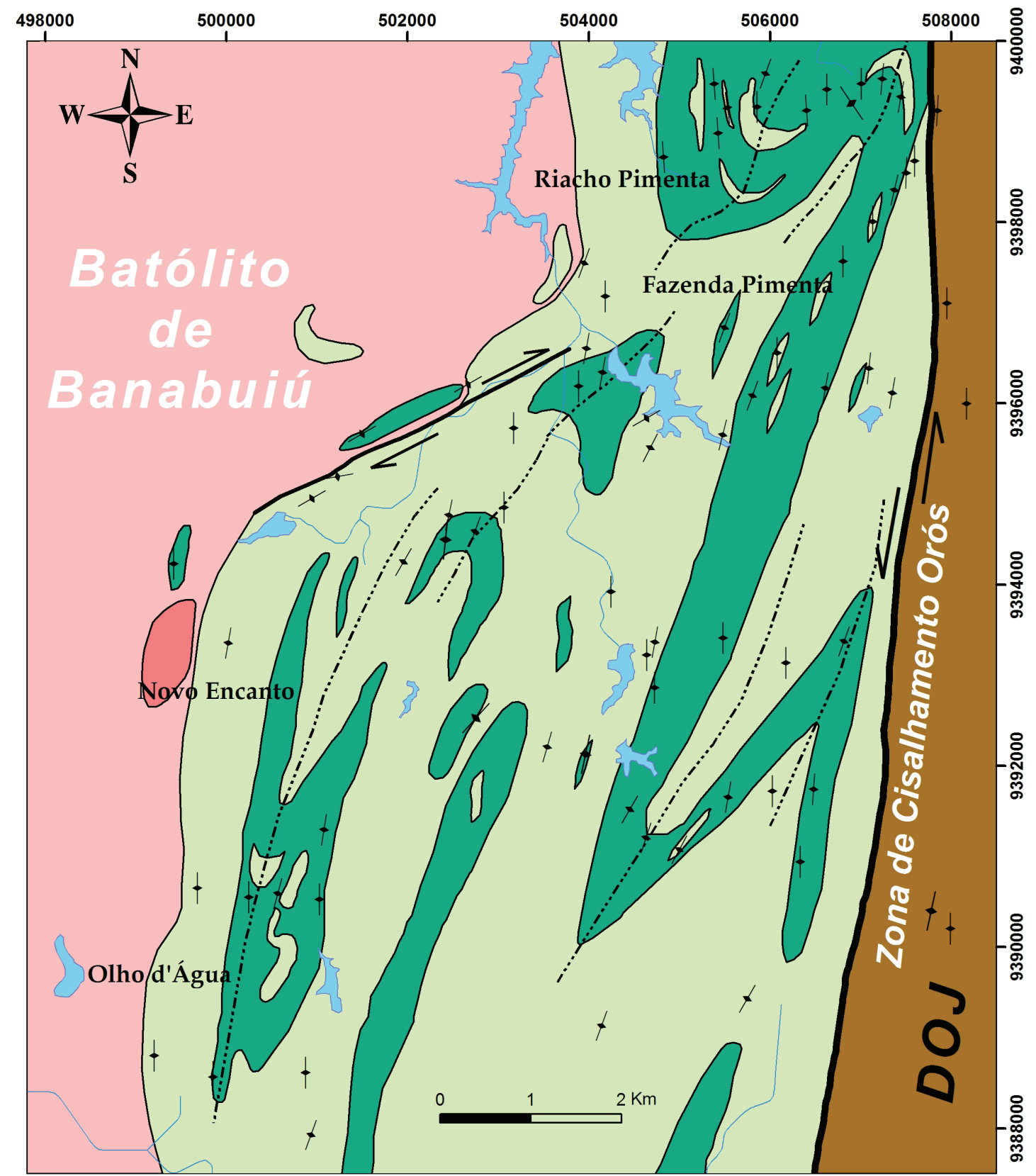

Domínio Ceará Central (DCC)

Domínio Orós-Jaguaribe (DOJ)

Complexo Gnáissico-Migmatítico Granitos Brasilianos

Ortognaisses bandados

Metatexitos estromáticos

†oliação Regional

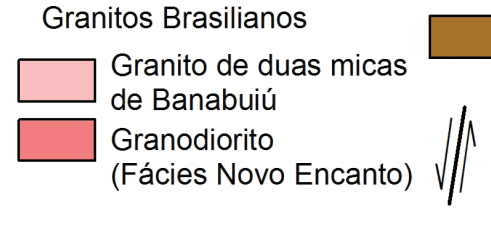

Seq. metavulcano-sedimentar da Faixa Orós de Banabuiú Granodiorito Zona de cisalhamento esquerda Zona de cisalhamento direita

Figura 2. Mapa Geológico da região sul do Batólito de Banabuiú, onde ocorre o corpo de granodiorito biotítico (fácies Novo Encanto)

Figure 2. Geological map of the south region of the Banabuiú Batholith, where occurs the biotite granodiorite body (Novo Encanto facies). 
de geoquímica de rocha total, usando o pacote analítico 4LITHORESEARCH. Os elementos maiores foram analisados por ICP-AES (Inductively Coupled Plasma- Atomic Emission Spectrometry), enquanto a determinação das concentrações em elementos traço foi realizada por ICP-MS (Inductively Coupled Plasma- Mass Spectrometry).

\section{Resultados e discussões}

\subsection{Observações de campo}

À escala do afloramento, o batólito de Banabuiú é composto por um granito leucocrático, de grão fino a médio, aspeto bastante homogêneo, contendo quartzo, feldspato potássico, plagioclásio e proporções semelhantes de moscovita e biotita como constituintes essenciais (Fig. 3A e 3B). Embora localmente, possa exibir uma foliação de fluxo magmático definida pelo alinhamento das micas. Na periferia do maciço, encontram-se, por vezes, megaencraves lenticulares da encaixante migmatítica, parcialmente digeridos pelo granito hospedeiro. O granito pode apresentar também schlieren biotíticos e pequenos enclaves metassedimentares com textura xistosa dispersos no seu interior (Lima, 2014).

Próximo da povoação de Novo Encanto, na porção oriental do batólito, o granito de duas micas de Banabuiú contata com um pequeno corpo de granodiorito biotítico (fácies Novo Encanto) (Fig. 2). O granodiorito biotítico de Novo Encanto distingue-se claramente do granito de Banabuiú pela sua tonalidade cinza e granulação muito fina (Fig. 3C). A coexistência e mistura parcial (mixing / mingling) entre o magma granítico e o magma granodiorítico são amplamente evidenciadas pelo desenvolvimento de contatos interdigitados entre os dois litótipos, pela ocorrência pontual de faixas irregulares de rochas com características transicionais (híbridas) nas zonas de interface e pela presença de enxames de enclaves microgranulares de composição granodiorítica no seio do granito (Fig. 3D, 3E e 3F).

Os enclaves microgranulares têm formas ovaladas e dimensões variáveis. Apresentam, em geral, bordos enriquecidos em biotita, testemunhando os efeitos da reação entre magmas de composição distinta (Fig. 3E). Nalguns casos, os seus contatos com o granito hospedeiro são difusos, lobados ou crenulados, enquanto noutros são bruscos e bem definidos, o que poderá refletir diferentes estágios de interacção entre o magma mais máfico e o magma félsico. As feições observadas sugerem que os enclaves correspondem a glóbulos de magma granodiorítico englobados no magma granítico enquanto este não estava completamente cristalizado (e.g. Donaire etal., 2005; Vernon, 2008; Gill, 2010). Devido ao contraste de temperatura e viscosidade com o magma granítico hospedeiro, 0 magma granodiorítico resfriou mais rapidamente e adquiriu uma textura granular muito fina (e.g. Donaire et al., 2005; Vernon, 2008; Gill, 2010).

No seu conjunto, as relações descritas confirmam a existência de uma estreita associação temporal entre a intrusão do granito de Banabuiú e a do granodiorito de Novo Encanto e sugerem a intervenção de processos de mistura de magmas (mixing / mingling) na sua petrogênese. As relações de mixing e mingling observadas no batólito de Banabuiú não são únicas na Província Borborema. Estas relações mereceram especial atenção, por parte dos invertigadores, nomeadamente nos batólitos de Quixadá e Quixeramobim (Domínio Ceará Central) e em vários batólitos distribuídos pelo Domínio Rio Grande do Norte e Zona Transversal da Província Borborema (e.g. Mariano \& Sial, 1988, 1990; Almeida, 1995; Neves \& Mariano, 1997; Mariano, 1999; Almeida \& Ulbrich, 2001).

\section{2 Petrografia}

Em termos petrográficos, o granito de duas micas de Banabuiú é caraterizado por uma textura granular hipidiomórfica de granulação fina a média e uma paragênese mineral composta por quartzo, microclina, plagioclásio (oligoclásioalbita), moscovita, biotita, apatita, zircão, monazita e minerais opacos (Fig. 4A). A clorita e a sericita estão frequentemente presentes como minerais secundários resultantes da alteração da biotita e do plagioclásio, respetivamente. A maioria das amostras analisadas possui um fabric isotrópico, embora se reconheça, por vezes, uma foliação de 

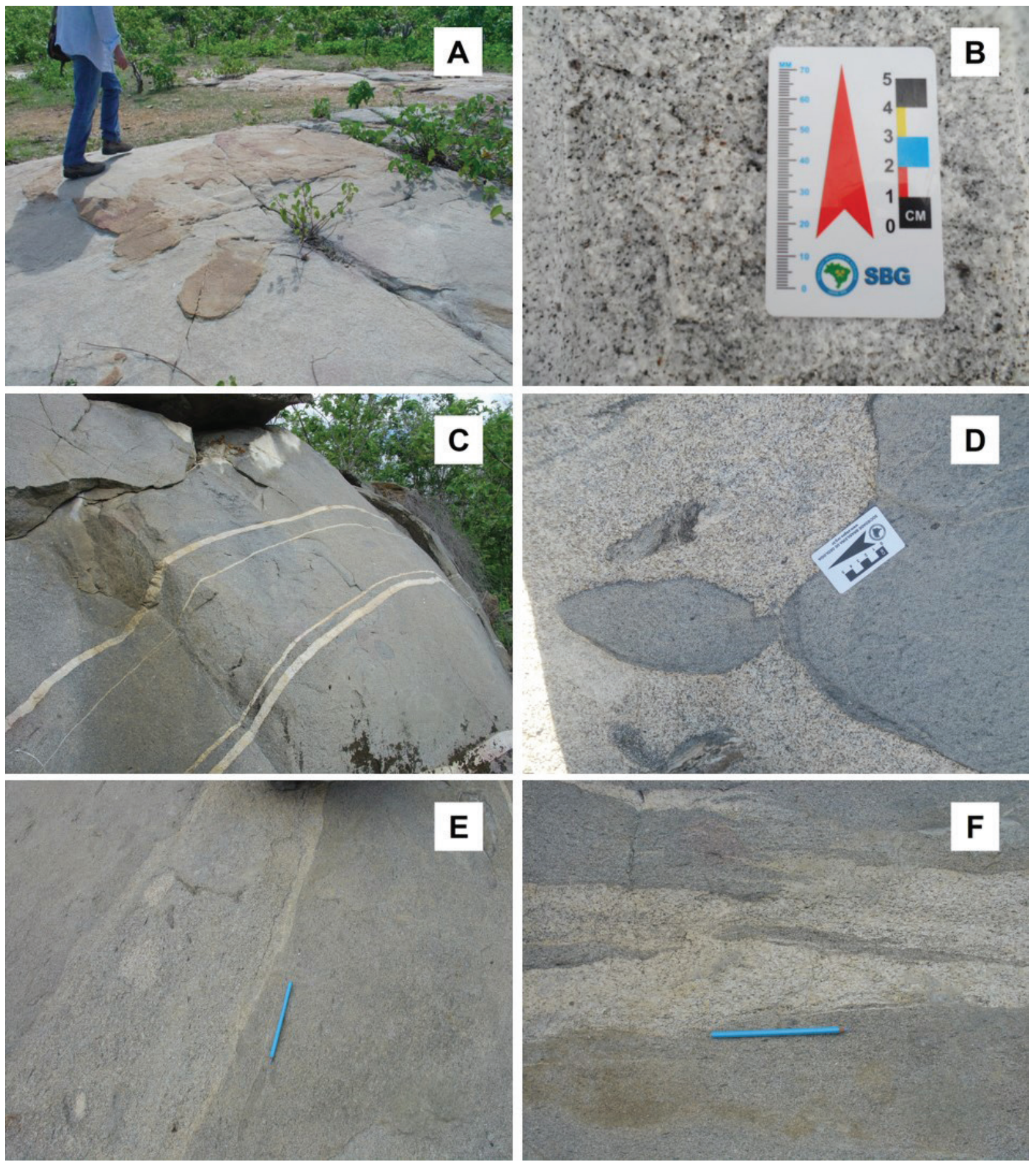

Figura 3. Aspectos de campo das fácies do batólito de Banabuiú. A) Laje de granito de duas micas de Banabuiú; B) Aspecto de detalhe do granito de duas micas; C) Afloramento de granodiorito biotítico cortado por veios pegmatíticos; D) Enclaves ovalados de granodiorito no seio do granito de duas micas; E) Contatos interdigitados entre o granodiorito biotítico de Novo Encanto e o granito de duas micas de Banabuiú; F) Zona de mistura entre o granodiorito biotítico de Novo Encanto e o granito de duas micas de Banabuiú, constituída por rochas híbridas com enclaves das duas fácies principais.

Figure 3. Field aspects of Banabuiú batholith facies. A) Outcrop of two-mica granite; B) Texture detail of two-mica granite; C) Biotite granodiorite outcrop intruded by pegmatitic veins; D) Oval enclaves inside of the two-mica granite; E) Interdigitated contacts between biotite granodiorite and two-mica granite; F) Mixing zone between biotite granodiorite and two-mica granite. Note that the enclaves of the main facies are surrounded by the hybrid rock. 
fluxo magmático definida pelo alinhamento de cristais de moscovita e de biotita (Fig. 4B).

O quartzo ocorre em grãos predominantemente anédricos e intersticiais, com dimensões variando entre 0,1 e $3 \mathrm{~mm}$, mostrando, com frequência, extinção ondulante e subgranulação. Aparece ainda sob a forma de pequenas inclusões goticulares no interior dos cristais de feldspato potássico e de plagioclásio. O feldspato potássico é a microclina e os seus cristais possuem dimensões máximas de $3 \mathrm{~mm}$ e são geralmente xenomórficos; apresentam a macla em xadrez típica e intercrescimentos micropertíticos. O plagioclásio tende a constituir cristais euédricos a subédricos $(0,25-1 \mathrm{~mm})$, com geminação polissintética segundo a Lei da Albita e zonamento ótico pouco nítido. A determinação da sua composição pelo método de Michel-Levi permitiu classificá-lo como oligoclásio $\left(A n_{11}\right)$. A substituição dos cristais de plagioclásio por pequenas palhetas alongadas de moscovita secundária (sericita) é comum. As micas perfazem cerca de $15 \%$ do volume total deste granito. A biotita tem pleocroísmo forte entre o bege (a) e o castanho-avermelhado $(\mathrm{Y}$ e $\beta$ ), hábito dominantemente subdiomórfico e dimensões máximas de 1,5 mm; pode mostrar alguma alteração para clorita, particularmente ao longo dos planos de clivagem. A moscovita primária está presente em cristais subédricos isolados que exibem, muito esporadicamente, clivagens arqueadas e extinção ondulante. Por último, a apatita, o zircão, a monazita e os minerais opacos ocorrem inclusos nas fases minerais principais, sobretudo na biotita.
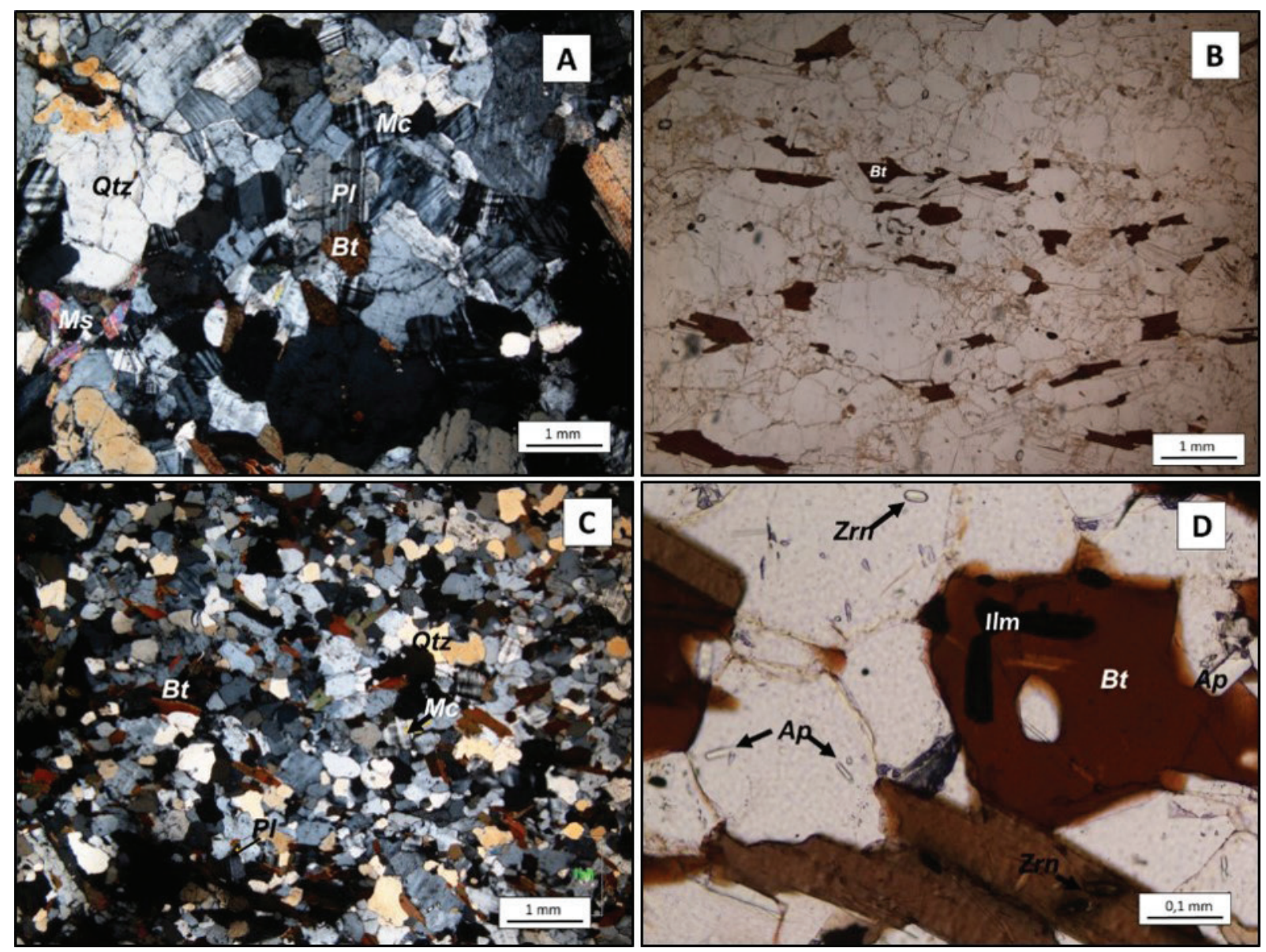

Figura 4. Caraterísticas petrográficas das fácies do Batólito de Banabuiú. A) Aspecto microscópico do granito de duas micas (Bt = biotita; $\mathrm{Pl}=$ plagioclásio; $\mathrm{Qtz}=$ quartzo; $\mathrm{Mc}=$ microclina; $\mathrm{Ms}=$ moscovita); $\mathrm{B}$ ) Foliação de fluxo magmático no granito de duas micas, definida pelo alinhamento preferencial dos minerais micáceos; C) Aspeto microscópico do granodiorito biotítico; D) Microfotografia de detalhe do granodiorito biotítico, mostrando minerais acessórios (Zrn = zircão; Ap = apatita; Ilm = ilmenita).

Figure 4. Petrographic features of Banabuiú batholith facies. A) Microscopic aspect of two-mica granite (Bt= biotite; $\mathrm{Pl}=$ plagioclase; $\mathrm{Qtz}=$ quartz; $\mathrm{Mc}=$ microcline; Ms=muscovite); B) Two-mica granite showing magmatic flow foliation defined by the alignment of phyllosilicates; $C$ ) Microscopic aspect of biotite granodiorite; D) Detail of biotite granodiorite, showing accessory minerals like apatite (Ap), IImenite (IIm) and zircon (Zrn). 
O granodiorito biotítico de Novo Encanto possui uma assembleia mineral formada por quartzo, plagioclásio, microclina, biotita, zircão, apatita e minerais opacos; apresenta textura hipidiomórfica equigranular de granulação fina (Fig. 4C). O quartzo ocorre em grãos submilimétricos a milimétricos, essencialmente anédricos, enquanto o plagioclásio e a microclina constituem cristais de dimensões semelhantes à do quartzo, variando de hipidiomórficos a xenomórficos (Fig. 4C). A biotita está geralmente presente como cristais de hábito tabular, com pleocroísmo forte em tons de marrom, contendo abundantes inclusões de minerais opacos, apatita e zircão (Fig. 4D); sua abundância nesta rocha pode atingir cerca de $20 \%$ da moda. Os minerais opacos ocorrem sob a forma de cristais prismáticos, com secções basais hexagonais, devendo corresponder maioritariamente a ilmenita (Fig. 4D). A apatita e o zircão também constituem cristais dominantemente idiomórficos que, no caso da apatita, chegam a atingir dimensões de 0,25 mm (Fig. 4D).

Relativamente ao granito de Banabuiú, a fácies de Novo Encanto apresenta quantidades significativamente mais elevadas de plagioclásio, biotita e minerais acessórios, sendo de realçar ainda o caráter mais cálcico do seu plagioclásio (Oligoclásio = An28), a maior abundância e dimensão dos minerais acessórios e a ausência de moscovita primária.

\subsection{Geoquímica}

As composições químicas das amostras estudadas, incluindo elementos maiores, traço e terras raras (ETR), encontram-se compiladas nas tabelas 1, 2, 3 e 4.

No diagrama de classificação R1R2 proposto por La Roche et al. (1980), as amostras do granito de Banabuiú classificamse maioritariamente como sienogranitos, ao passo que as amostras do granodiorito biotítico de Novo Encanto se projetam no campo dos granodioritos (Fig. 5A), em concordância com os dados petrográficos. Verifica-se, por outro lado, que a distribuição das amostras analisadas no diagrama A-B de Debon \& Le Fort (1983, 1988) permite estabelecer uma distinção clara entre estas duas unidades plutônicas (Fig. 5B). Enquanto as amostras do granodiorito de Novo Encanto são fracamente peraluminosas $(A<20)$ e se projetam no domínio em que a biotita é a única mica presente, as do granito de Banabuiú concentram-se no campo dos leucogranitos fortemente peraluminosos, com moscovita > biotita ou biotita > moscovita (Fig. 5B). De acordo com os critérios definidos pelos autores do diagrama, as características químicomineralógicas do granito de Banabuiú são compatíveis com uma derivação por anatexia de fontes metassedimentares supracrustais (filiação de tipo S, Chappell \& White, 1974, 1984, 1992). O reduzido espectro de variabilidade química e a predominância de razões $A / C N K$ com valores superiores a 1,1 neste granito $\left(\mathrm{SiO}_{2}=\right.$ $72,57-75,22 \% ; A / C N K=1,06-1,24$ ) corroboram a sua classificação como um granitóide de tipo-S.

Em contraste, o granodiorito biotítico de Novo Encanto exibe um carácter fracamente peraluminoso $(\mathrm{A} / \mathrm{CNK}=1,05-1,06)$, o que aliado à sua composição mais máfica $\left(\mathrm{SiO}_{2}=\right.$ 64,8 - 66,4\%), aponta para uma provável origem por fusão parcial de protólitos granulíticos metaígneos da crusta inferior (filiação de tipo I- Chappell \& White, 1974, 1984, 1992) ou por mistura de magmas félsicos de anatexia crustal com líquidos máficos de proveniência mantélica (filiação de tipo H- Castro et al., 1991).

As diferenças composicionais entre as rochas das duas intrusões ficam também bem evidenciadas nos diagramas binários de variação química, usando $\mathrm{o} \quad \mathrm{Fe}_{2} \mathrm{O}_{3}$ total como índice de diferenciação. As amostras do granito de duas micas de Banabuiú definem tendências evolutivas relativamente coerentes, marcadas por um empobrecimento sistemático em MgO, $\mathrm{MnO}, \mathrm{TiO}_{2}, \mathrm{CaO}, \mathrm{Sr}, \mathrm{Ba}, \mathrm{Zr}$, Th, Hf e $\sum$ ETR e um aumento em $\mathrm{K}_{2} \mathrm{O}$ com a diminuição de $\mathrm{Fe}_{2} \mathrm{O}_{3} \mathrm{~T}$ (Fig. 6 e 7). Admite-se, por isso, que a evolução do magma granítico tenha sido, pelo menos em parte, controlada por processos de cristalização fracionada envolvendo plagioclásio ( $\mathrm{CaO}, \mathrm{Sr}$ ), biotita $\left(\mathrm{MgO}, \mathrm{TiO}_{2}, \mathrm{Ba}, \mathrm{Nb}, \mathrm{Th}\right)$, ilmenita $\left(\mathrm{TiO}_{2}\right)$, apatita/monazita (LETR) e zircão (Zr, Th, Hf e ETR Pesadas). 
Tabela 1. Composição química em elementos maiores (\% de peso) e traço (ppm) das amostras de Granito de duas micas de Banabuiú (análises geoquímicas de rocha total extraídas de Lima (2014))

Table 1. Major (wt.\%) and trace (ppm) element composition of two-mica Banabuiú granite (extracted from Lima (2014))

\begin{tabular}{|c|c|c|c|c|c|c|c|c|c|}
\hline \multicolumn{10}{|c|}{ Granito de duas micas de Banabuiú } \\
\hline & M41.1 & M44.1 & MIO1 & MI 184 & MI 93A & M 137 & M 148.1 & MI 206 & MI 212 \\
\hline $\mathrm{SiO}_{2}$ & 72,57 & 73,07 & 74,01 & 75,22 & 73,07 & 74,16 & 75,16 & 73,74 & 74,08 \\
\hline $\mathrm{Al}_{2} \mathrm{O}_{3}$ & 14,5 & 14,96 & 13,63 & 13,89 & 14,67 & 14,33 & 13,81 & 14,27 & 14,23 \\
\hline $\mathrm{Fe}_{2} \mathrm{O}_{3}(\mathrm{~T})$ & 1,24 & 1,6 & 1,35 & 1,27 & 2,41 & 1,26 & 1,31 & 1,64 & 1,34 \\
\hline MnO & 0,022 & 0,022 & 0,018 & 0,016 & 0,032 & 0,019 & 0,037 & 0,029 & 0,034 \\
\hline MgO & 0,3 & 0,29 & 0,18 & 0,19 & 0,48 & 0,26 & 0,22 & 0,29 & 0,22 \\
\hline $\mathrm{CaO}$ & 0,8 & 0,74 & 0,88 & 0,82 & 1,55 & 1,2 & 1,11 & 1,33 & 1,05 \\
\hline $\mathrm{Na}_{2} \mathrm{O}$ & 2,99 & 3,04 & 3,17 & 3,07 & 4,12 & 3,78 & 3,71 & 3,45 & 3,69 \\
\hline $\mathrm{K}_{2} \mathrm{O}$ & 4,94 & 5,26 & 5,17 & 5,27 & 3,23 & 4,69 & 4,51 & 4,18 & 4,85 \\
\hline $\mathrm{TiO}_{2}$ & 0,128 & 0,195 & 0,121 & 0,116 & 0,267 & 0,155 & 0,116 & 0,206 & 0,118 \\
\hline $\mathrm{P}_{2} \mathrm{O}_{5}$ & 0,36 & 0,33 & 0,08 & 0,1 & 0,15 & 0,13 & 0,08 & 0,07 & 0,11 \\
\hline LOI & 1,5 & 1,21 & 0,61 & 0,68 & 0,93 & 0,42 & 0,09 & 0,43 & 0,5 \\
\hline Total & 99,37 & 100,7 & 99,23 & 100,6 & 100,9 & 100,4 & 100,2 & 99,63 & 100,2 \\
\hline Sc & 2 & 2 & 3 & 3 & 3 & 2 & 3 & 4 & 2 \\
\hline $\mathrm{Be}$ & 6 & 5 & 3 & 3 & 2 & 3 & 7 & 3 & 5 \\
\hline v & $<5$ & 5 & $<5$ & $<5$ & 18 & 10 & 10 & 14 & 7 \\
\hline $\mathrm{Cr}$ & $<20$ & $<20$ & 20 & $<20$ & $<20$ & $<20$ & $<20$ & $<20$ & $<20$ \\
\hline Co & 2 & 5 & 1 & 1 & 3 & 2 & 1 & 2 & 1 \\
\hline $\mathrm{Ni}$ & $<20$ & $<20$ & $<20$ & $<20$ & $<20$ & $<20$ & $<20$ & $<20$ & $<20$ \\
\hline $\mathrm{Cu}$ & $<10$ & $<10$ & $<10$ & 30 & 30 & $<10$ & $<10$ & $<10$ & 20 \\
\hline $\mathrm{Zn}$ & 210 & 110 & 40 & 40 & 80 & 40 & 40 & 60 & 50 \\
\hline Ga & 26 & 25 & 19 & 20 & 23 & 22 & 21 & 24 & 22 \\
\hline $\mathrm{Ge}$ & 2,1 & 1,9 & 1,1 & 1,1 & 0,8 & 1,2 & 1,8 & 1,2 & 1,5 \\
\hline As & $<5$ & $<5$ & $<5$ & $<5$ & $<5$ & $<5$ & $<5$ & $<5$ & $<5$ \\
\hline $\mathbf{R b}$ & 318 & 308 & 248 & 256 & 227 & 187 & 275 & 227 & 262 \\
\hline $\mathrm{Sr}$ & 103 & 93 & 115 & 111 & 247 & 228 & 135 & 227 & 134 \\
\hline$Y$ & 7,1 & 6,5 & 6,9 & 6,4 & 12,5 & 5,5 & 14,6 & 12,6 & 11,8 \\
\hline $\mathrm{Zr}$ & 60 & 92 & 107 & 91 & 262 & 92 & 110 & 166 & 111 \\
\hline $\mathrm{Nb}$ & 8,6 & 7,6 & 7,6 & 7,5 & 12 & 5,5 & 13 & 16,8 & 12,4 \\
\hline Mo & $<2$ & $<2$ & $<2$ & $<2$ & $<2$ & $<2$ & $<2$ & $<2$ & $<2$ \\
\hline $\mathrm{Ag}$ & $<0,5$ & $<0,5$ & $<0,5$ & $<0,5$ & $<0,5$ & 0,8 & 1,3 & $<0.5$ & $<0.5$ \\
\hline In & $<0,1$ & $<0,1$ & $<0,1$ & $<0,1$ & $<0,1$ & $<0,1$ & $<0,1$ & $<0.1$ & $<0.1$ \\
\hline Sn & 3 & 3 & 1 & 1 & 3 & 2 & 8 & 4 & 4 \\
\hline $\mathrm{Sb}$ & $<0,2$ & $<0,2$ & 0,9 & 1,4 & 1 & $<0,2$ & $<0,2$ & 0,4 & 1,8 \\
\hline Cs & 2,8 & 4 & 2,1 & 2,1 & 2,6 & 3,1 & 12,2 & 2,7 & 7,4 \\
\hline $\mathrm{Ba}$ & 304 & 425 & 768 & 670 & 1668 & 966 & 686 & 1246 & 742 \\
\hline $\mathrm{Hf}$ & 2 & 2,9 & 3,7 & 3,3 & 6,9 & 2,5 & 3,2 & 4,8 & 3,4 \\
\hline Ta & 0,92 & 0,72 & 1,13 & 1,04 & 0,86 & 0,47 & 2,81 & 1,95 & 2 \\
\hline$w$ & $<0,5$ & $<0,5$ & 0,5 & 0,6 & $<0,5$ & $<0,5$ & 0,6 & $<0.5$ & $<0.5$ \\
\hline TI & 1,24 & 1,26 & 1,16 & 1,33 & 1,34 & 1,17 & 1,81 & 1,6 & 1,5 \\
\hline $\mathrm{Pb}$ & 33 & 34 & 49 & 70 & 31 & 35 & 23 & 31 & 29 \\
\hline $\mathrm{Bi}$ & 0,2 & 0,3 & 3,8 & 3,7 & 0,2 & 0,2 & 0,5 & $<0.1$ & 0,4 \\
\hline Th & 9,48 & 16,2 & 27,4 & 24,4 & 51 & 12,1 & 30,9 & 33,6 & 27 \\
\hline U & 3,74 & 2,85 & 4,67 & 3,26 & 5,17 & 2,96 & 3,71 & 3,22 & 5,9 \\
\hline
\end{tabular}

Apesar do reduzido número de amostras analisadas, a fácies Novo Encanto projeta-se como um conjunto independente de pontos nos diagramas de variação química (Fig. 6 e 7). Para além dos baixos índices de peraluminosidade, as amostras de granodiorito apresentam teores elevados em $\mathrm{MgO}, \mathrm{TiO}_{2}, \mathrm{MnO}, \mathrm{CaO}, \mathrm{P}_{2} \mathrm{O}_{5}, \mathrm{Nb}$, ¿ETR, Zr, Sr e Ba, o que vem novamente apoiar a hipótese deste magma ter sido gerado por hibridização entre líquidos de composição e proveniência distinta.

Ressalte-se ainda que a existência de um gap composicional entre as amostras do granodiorito biotítico de Novo Encanto e as do granito de Banabuiú levam a descartar uma possível relação de consanguinidade entre eles, confirmando a independência genética entre os dois tipos de magmas. Contudo, as amostras de ambas as intrusões parecem dispor-se segundo alinhamentos retilíneos em muitos dos diagramas de variação química (ex: $\mathrm{SiO}_{2}, \mathrm{TiO}_{2}, \mathrm{MnO}, \mathrm{MgO}$, $\mathrm{CaO}, \Sigma \mathrm{ETR}, \mathrm{Zr}$, Sr e Ba), o que poderá indiciar a atuação de processos de interação física e química, de extensão variável, entre os magmas granodiorítico e granítico, em conformidade com as relações de mixing e mingling observadas em campo (Fig. 6 e 7 ).

Mostram-se na figura 8, os padrões de ETR normalizados ao condrito de Evensen et al. (1978) para as amostras de granito de duas 
Tabela 2. Composição química em elementos maiores (\% de peso) e traço (ppm) das amostras de Granito de duas micas de Banabuiú e de Granodiorito Biotítico (análises geoquímicas de rocha total extraídas de Lima (2014) e Martins (2014)). Table 2. Major (wt.\%) and trace ( $\mathrm{ppm}$ ) element composition of two-mica Banabuiú granite and biotite granodiorite (extracted from Lima (2014) and Martins (2014))

\begin{tabular}{|c|c|c|c|c|c|c|c|c|c|}
\hline & \multicolumn{7}{|c|}{ Granito de duas micas de Banabuiú } & \multicolumn{2}{|c|}{ Granodiorito biotítico } \\
\hline & M 144.1 & MI 214 & M 49.1 & M 95.1 & M 140.1 & M 142.1 & M 145.1 & FB-65 & M 130.1 \\
\hline $\mathrm{SiO}_{2}$ & 74,33 & 74,82 & 72,91 & 72,58 & 73,88 & 75 & 74,55 & 66,37 & 64,84 \\
\hline $\mathrm{Al}_{2} \mathrm{O}_{3}$ & 14,59 & 13,41 & 14,95 & 14,19 & 14,62 & 14,5 & 14,28 & 14,8 & 15,9 \\
\hline $\mathrm{Fe}_{2} \mathrm{O}_{3}(\mathrm{~T})$ & 1,57 & 1,38 & 1,86 & 1,53 & 1,32 & 1,07 & 1 & 4,26 & 4,79 \\
\hline MnO & 0,028 & 0,018 & 0,021 & 0,02 & 0,022 & 0,028 & 0,018 & 0,05 & 0,058 \\
\hline MgO & 0,28 & 0,21 & 0,35 & 0,3 & 0,23 & 0,14 & 0,17 & 1,17 & 1,43 \\
\hline $\mathrm{CaO}$ & 0,77 & 0,52 & 0,86 & 0,85 & 0,93 & 0,53 & 0,55 & 2,24 & 2,62 \\
\hline $\mathrm{Na}_{2} \mathrm{O}$ & 3,25 & 2,59 & 3,17 & 2,86 & 3,7 & 3,52 & 3,16 & 3,15 & 3,31 \\
\hline $\mathrm{K}_{2} \mathrm{O}$ & 4,86 & 5,99 & 5,17 & 5,43 & 4,9 & 4,76 & 5 & 4,39 & 4,36 \\
\hline $\mathrm{TiO}_{2}$ & 0,21 & 0,143 & 0,294 & 0,214 & 0,142 & 0,096 & 0,084 & 0,94 & 1,138 \\
\hline $\mathrm{P}_{2} \mathrm{O}_{5}$ & 0,23 & 0,2 & 0,33 & 0,25 & 0,21 & 0,26 & 0,46 & 0,41 & 0,51 \\
\hline LOI & 0,63 & 0,53 & 1 & 0,84 & 0,45 & 1,07 & 0,74 & 0,55 & 0,52 \\
\hline Total & 100,8 & 99,81 & 100,9 & 99,07 & 100,4 & 101 & 100 & 98,34 & 99,48 \\
\hline Sc & 2 & 1 & 3 & 2 & 2 & 2 & 2 & 6 & 7 \\
\hline $\mathrm{Be}$ & 8 & 2 & 4 & 2 & 6 & 6 & 5 & 3 & 4 \\
\hline v & 10 & $<5$ & 11 & 9 & 7 & 6 & $<5$ & 40 & 44 \\
\hline $\mathrm{Cr}$ & $<20$ & $<20$ & $<20$ & $<20$ & $<20$ & $<20$ & $<20$ & 50 & 40 \\
\hline Co & 2 & 1 & 3 & 3 & 1 & 2 & $<1$ & 9 & 10 \\
\hline $\mathrm{Ni}$ & $<20$ & $<20$ & $<20$ & $<20$ & $<20$ & $<20$ & $<20$ & $<20$ & $<20$ \\
\hline $\mathrm{Cu}$ & $<10$ & 420 & $<10$ & $<10$ & $<10$ & $<10$ & $<10$ & 60 & $<10$ \\
\hline $\mathrm{Zn}$ & 80 & 50 & 80 & 40 & 70 & 40 & 60 & 100 & 180 \\
\hline Ga & 24 & 17 & 28 & 23 & 24 & 26 & 21 & 27 & 26 \\
\hline Ge & 2,3 & 0,9 & 1,9 & 1,5 & 1,9 & 2,4 & 2,6 & 2,8 & 1,8 \\
\hline As & $<5$ & $<5$ & $<5$ & $<5$ & $<5$ & $<5$ & $<5$ & $<5$ & $<5$ \\
\hline $\mathbf{R b}$ & 311 & 268 & 368 & 214 & 333 & 277 & 282 & 210 & 205 \\
\hline Sr & 103 & 112 & 96 & 112 & 131 & 67 & 68 & 342 & 478 \\
\hline Y & 5,3 & 9,8 & 7,3 & 9,6 & 7,7 & 7,9 & 8,2 & 16,1 & 19,1 \\
\hline $\mathrm{Zr}$ & 99 & 127 & 161 & 114 & 83 & 49 & 43 & 413 & 493 \\
\hline $\mathrm{Nb}$ & 9 & 7,5 & 8,7 & 4,3 & 6,1 & 6,9 & 8,1 & 12,2 & 22,3 \\
\hline Mo & $<2$ & $<2$ & $<2$ & $<2$ & $<2$ & $<2$ & $<2$ & $<2$ & $<2$ \\
\hline $\mathrm{Ag}$ & 0,9 & 2,4 & 2 & 1,2 & 0,9 & $<0,5$ & $<0,5$ & 2,6 & 1,9 \\
\hline In & $<0,1$ & $<0,1$ & $<0,1$ & $<0,1$ & $<0,1$ & $<0,1$ & $<0,1$ & $<0,1$ & $<0,1$ \\
\hline Sn & 4 & 1 & 2 & 2 & 3 & 4 & 2 & 7 & 3 \\
\hline Sb & $<0,2$ & $<0,2$ & $<0,2$ & $<0,2$ & $<0,2$ & $<0,2$ & $<0,2$ & 0,4 & $<0,2$ \\
\hline Cs & 4 & 1,9 & 3,7 & 2 & 11,4 & 2,5 & 3,4 & 2,6 & 3,3 \\
\hline $\mathrm{Ba}$ & 407 & 905 & 432 & 458 & 604 & 218 & 265 & 1188 & 1429 \\
\hline $\mathrm{Hf}$ & 2,7 & 4,1 & 4 & 3,3 & 2,2 & 1,8 & 1,4 & 8,7 & 12,9 \\
\hline Ta & 1,89 & 0,8 & 0,63 & 0,35 & 0,64 & 1,01 & 0,86 & 0,88 & 1,02 \\
\hline w & 1,9 & $<0.5$ & 1,6 & 1 & 0,9 & 2,3 & 0,7 & $<0.5$ & $<0.5$ \\
\hline TI & 2,06 & 1,62 & 2,18 & 1,29 & 2,37 & 1,82 & 1,64 & 0,85 & 0,86 \\
\hline $\mathrm{Pb}$ & 23 & 42 & 26 & 47 & 31 & 33 & 28 & 25 & 27 \\
\hline $\mathrm{Bi}$ & 0,3 & 1,1 & 0,1 & $<0.1$ & 0,2 & 2,6 & 0,3 & $<0.1$ & $<0.1$ \\
\hline Th & 18,9 & 25,1 & 34,1 & 22,6 & 10,9 & 6,72 & 3,65 & 29,5 & 30,9 \\
\hline U & 2,65 & 3,25 & 5,37 & 3,86 & 4,62 & 4,04 & 1,89 & 2,19 & 2,5 \\
\hline
\end{tabular}


Tabela 3. Composição de ETR (ppm) para as amostras de Granito de duas micas de Banabuiú (extraído de (Lima 2014)) Table 3. REE composition of two-mica Banabuiú granite (extracted from Lima (2014))

\begin{tabular}{|c|c|c|c|c|c|c|c|c|c|}
\hline \multicolumn{10}{|c|}{ Granito de duas micas de Banabuiú } \\
\hline & M41.1 & M44.1 & MI 01 & MI 184 & MI 93A & M 137 & M 148.1 & MI 206 & MI 212 \\
\hline La & 19,8 & 32,6 & 43,5 & 37,2 & 125 & 28,5 & 43,8 & 79,9 & 45,5 \\
\hline $\mathrm{Ce}$ & 41,1 & 66,8 & 83,2 & 73,2 & 211 & 56,6 & 84,2 & 144 & 76,5 \\
\hline $\operatorname{Pr}$ & 4,98 & 8,04 & 8,21 & 7,36 & 18,7 & 5,83 & 8,04 & 12,6 & 7,01 \\
\hline Nd & 16,9 & 27,6 & 25,2 & 23,2 & 51,6 & 21,2 & 26,7 & 37,5 & 22,6 \\
\hline Sm & 3,68 & 5,67 & 4,52 & 4,2 & 7,99 & 4,34 & 4,59 & 6,24 & 4,04 \\
\hline Eu & 0,328 & 0,428 & 0,587 & 0,544 & 1,05 & 0,671 & 0,53 & 0,968 & 0,54 \\
\hline Gd & 2,29 & 3,12 & 1,53 & 1,71 & 4,56 & 2,95 & 3,51 & 3,82 & 3,11 \\
\hline Tb & 0,3 & 0,35 & 0,24 & 0,23 & 0,51 & 0,34 & 0,47 & 0,5 & 0,42 \\
\hline Dy & 1,41 & 1,46 & 1,24 & 1,13 & 2,26 & 1,29 & 2,61 & 2,34 & 2,02 \\
\hline Ho & 0,22 & 0,21 & 0,19 & 0,17 & 0,42 & 0,18 & 0,49 & 0,41 & 0,36 \\
\hline $\mathrm{Er}$ & 0,52 & 0,5 & 0,4 & 0,38 & 1,23 & 0,49 & 1,35 & 1,11 & 1,01 \\
\hline $\mathrm{Tm}$ & 0,065 & 0,061 & 0,049 & 0,048 & 0,184 & 0,066 & 0,19 & 0,154 & 0,146 \\
\hline $\mathrm{Yb}$ & 0,41 & 0,33 & 0,27 & 0,27 & 1,2 & 0,41 & 1,33 & 0,93 & 0,95 \\
\hline Lu & 0,064 & 0,046 & 0,03 & 0,032 & 0,19 & 0,069 & 0,21 & 0,132 & 0,124 \\
\hline$\sum$ REE & 92,07 & 147,22 & 169,17 & 149,67 & 425,89 & 122,94 & 178,02 & 290,6 & 164,33 \\
\hline $\mathrm{Eu} / \mathrm{Eu}^{*}$ & 0,32 & 0,28 & 0,55 & 0,53 & 0,49 & 0,54 & 0,39 & 0,56 & 0,45 \\
\hline $\mathrm{La}_{N} / \mathrm{Yb}_{\mathrm{N}}$ & 32,6 & 66,68 & 108,75 & 93 & 70,31 & 46,92 & 22,23 & 57,99 & 32,33 \\
\hline
\end{tabular}

Tabela 4. Composição química em ETR (ppm) para as amostras de Granito de duas micas de Banabuiú e de Granodiorito biotítico (extraído de Lima (2014) e Martins (2014))

Table 4. REE composition of two-mica granite and biotite granodiorite (extracted from Lima (2014) e Martins (2014))

\begin{tabular}{|c|c|c|c|c|c|c|c|c|c|}
\hline & \multicolumn{7}{|c|}{ Granito de duas micas de Banabuiú } & \multicolumn{2}{|c|}{ Granodiorito biotítico } \\
\hline & M 144.1 & MI 214 & M 49.1 & M 95.1 & M 140.1 & M 142.1 & M 145.1 & $F B-65$ & M 130.1 \\
\hline La & 37,8 & 50,5 & 56,3 & 41,5 & 24,5 & 18,5 & 9,22 & 91,4 & 77,4 \\
\hline $\mathrm{Ce}$ & 84,2 & 100 & 130 & 94,4 & 50,7 & 36,5 & 20,5 & 185 & 173 \\
\hline $\operatorname{Pr}$ & 9,04 & 8,87 & 14,4 & 10,3 & 5,23 & 3,94 & 2,58 & 21,8 & 18,7 \\
\hline Nd & 32,9 & 30 & 51,4 & 38,8 & 18,6 & 14 & 9,07 & 77 & 63,4 \\
\hline Sm & 6,22 & 5,65 & 8,87 & 7,75 & 3,88 & 3,47 & 2,51 & 11,1 & 9,98 \\
\hline Eu & 0,545 & 0,547 & 0,546 & 0,627 & 0,454 & 0,395 & 0,345 & 1,48 & 1,67 \\
\hline Gd & 3,8 & 3,75 & 4,78 & 4,79 & 2,66 & 2,74 & 2,21 & 5,56 & 5,79 \\
\hline Tb & 0,38 & 0,46 & 0,44 & 0,56 & 0,36 & 0,4 & 0,38 & 0,64 & 0,75 \\
\hline Dy & 1,3 & 2,04 & 1,71 & 2,29 & 1,58 & 1,72 & 1,76 & 2,98 & 3,67 \\
\hline Ho & 0,19 & 0,33 & 0,25 & 0,37 & 0,23 & 0,26 & 0,27 & 0,52 & 0,66 \\
\hline Er & 0,44 & 0,85 & 0,63 & 0,87 & 0,6 & 0,66 & 0,6 & 1,43 & 1,76 \\
\hline $\mathrm{Tm}$ & 0,052 & 0,112 & 0,077 & 0,1 & 0,073 & 0,082 & 0,068 & 0,185 & 0,236 \\
\hline Yb & 0,29 & 0,67 & 0,42 & 0,57 & 0,36 & 0,46 & 0,39 & 1,1 & 1,43 \\
\hline Lu & 0,04 & 0,094 & 0,061 & 0,08 & 0,048 & 0,067 & 0,056 & 0,165 & 0,213 \\
\hline$\sum$ REE & 177,2 & 203,87 & 269,88 & 203,01 & 109,28 & 83,2 & 49,96 & 400,36 & 358,66 \\
\hline Eu/Eu* & 0,32 & 0,34 & 0,23 & 0,29 & 0,41 & 0,38 & 0,44 & 0,51 & 0,62 \\
\hline $\mathrm{La}_{\mathrm{N}} / \mathrm{Yb}_{\mathrm{N}}$ & 87,98 & 50,88 & 90,48 & 49,14 & 45,94 & 27,15 & 15,96 & 56,08 & 36,53 \\
\hline
\end{tabular}



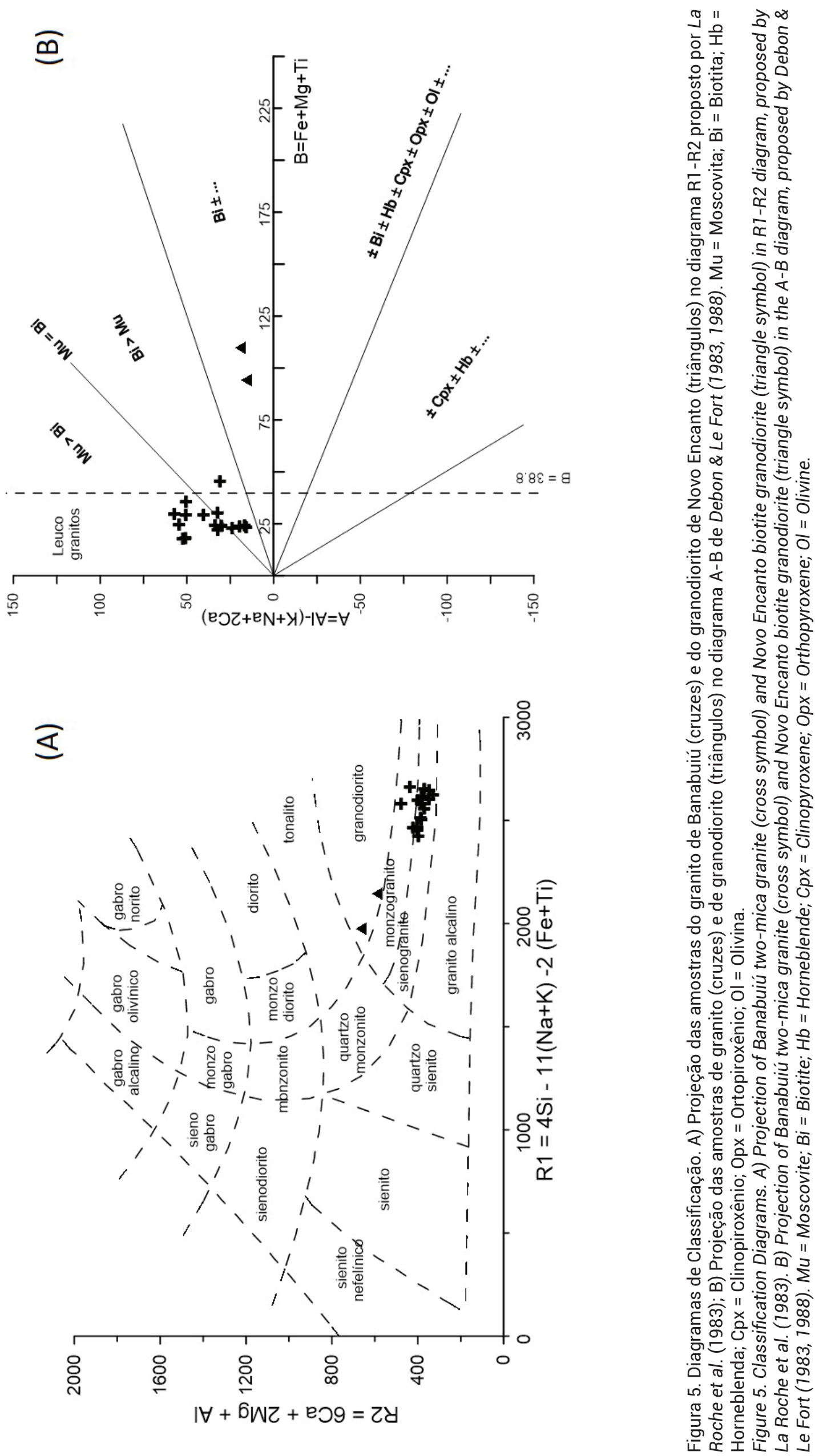

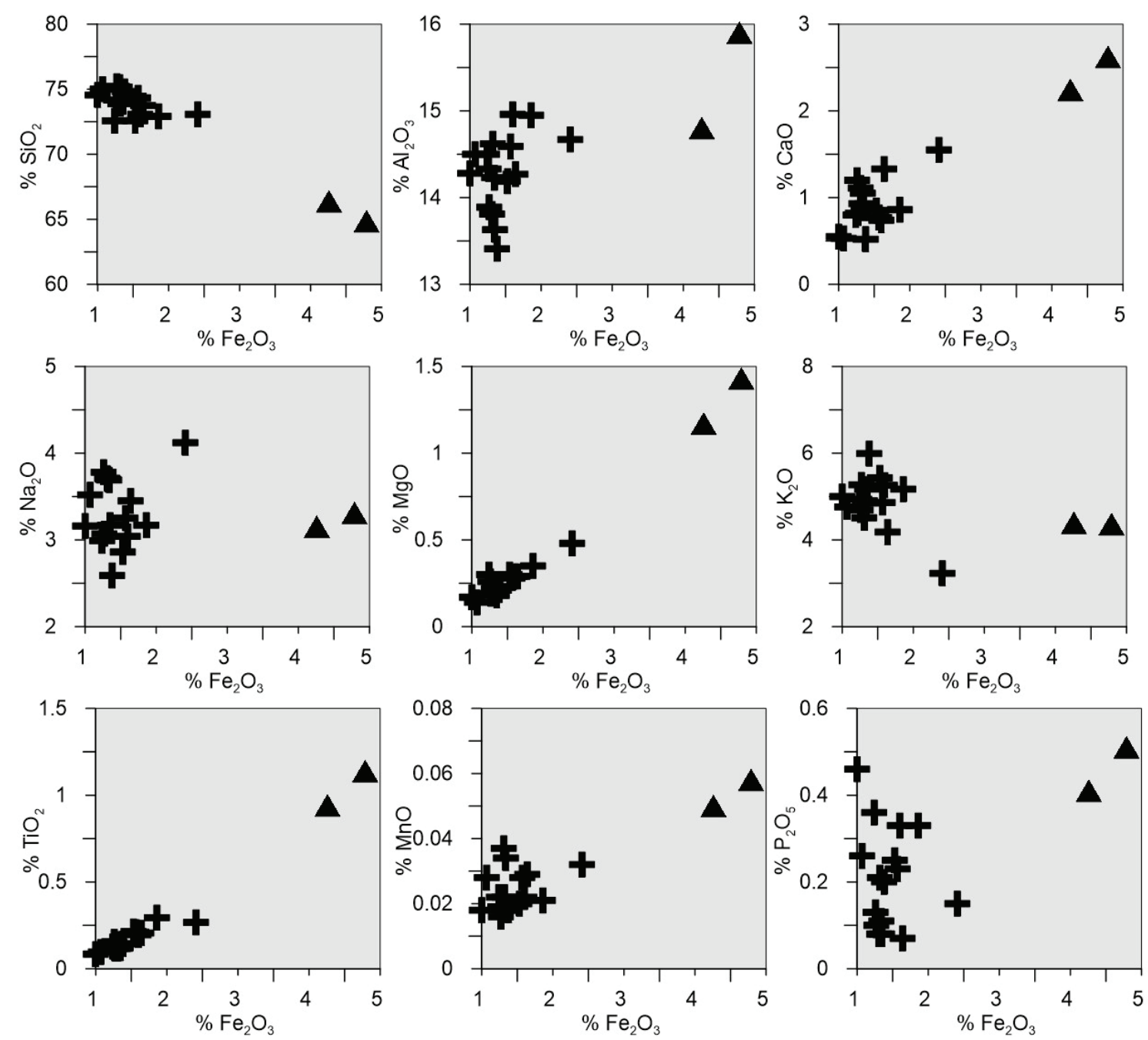

Figura 6. Diagramas de variação de elementos maiores para o granito de duas micas de Banabuiú (cruzes) e para o granodiorito biotítico de Novo Encanto (triângulos).

Figure 6. Major element variation diagrams of the Banabuiú two-mica granite (cross symbol) and Novo Encanto biotite granodiorite (triangle symbol).

micas e do granodiorito biotítico. As amostras da fácies granítica exibem perfis sub-paralelos entre si, caracterizados por um enriquecimento moderado a alto das ETR leves em relação às ETR pesadas ( $\mathrm{LaN} / \mathrm{YbN}=15,96-108,75)$ e anomalias negativas de Eu bem definidas $\left(\mathrm{Eu}_{\mathrm{N}} / \mathrm{Eu}_{\mathrm{N} *}=0,23-\right.$ 0,56). De uma forma geral, os teores em ETR tendem a diminuir com a evolução magmática e as anomalias negativas em európio tornamse mais pronunciadas (Fig. 8A), indicando que o fracionamento de minerais concentradores destes elementos, como o plagioclásio (Eu), apatita/monazita (ETR leves) e zircão (ETR pesadas) tiveram uma influência significativa na diferenciação magmática do batólito granítico. As razões relativamente elevadas de ETR leves/ ETR pesadas podem, por outro lado, refletir a retenção de minerais com preferência pelas ETR pesadas (como é o caso da granada) no resíduo formado durante os processos de anatexia crustal (e.g Patiño Douce \& McCarthy, 1998).

Comparativamente ao granito de Banabuiú, o granodiorito de Novo Encanto apresenta um considerável enriquecimento em ETR, particularmente em ETR leves e anomalias negativas de európio mais discretas ( $\mathrm{REE}=$ 358,66- 400,36 ppm; $\mathrm{La}_{N} / \mathrm{Yb}_{N}=36,53-56,08 ; \mathrm{Eu}_{N} /$ $\left.\mathrm{Eu}_{\mathrm{N} *}=0,51-0,62\right)$ (Fig. 8B). A maior abundância de minerais acessórios ricos em ETR (apatita, zircão e ilmenita) nesta fácies explica o enriquecimento em ETR observado (Donaire et al., 2005). Tendo em conta que a hibridização entre fundidos félsicos crustais e magmas básicos provenientes do manto pode produzir líquidos com anomalias 

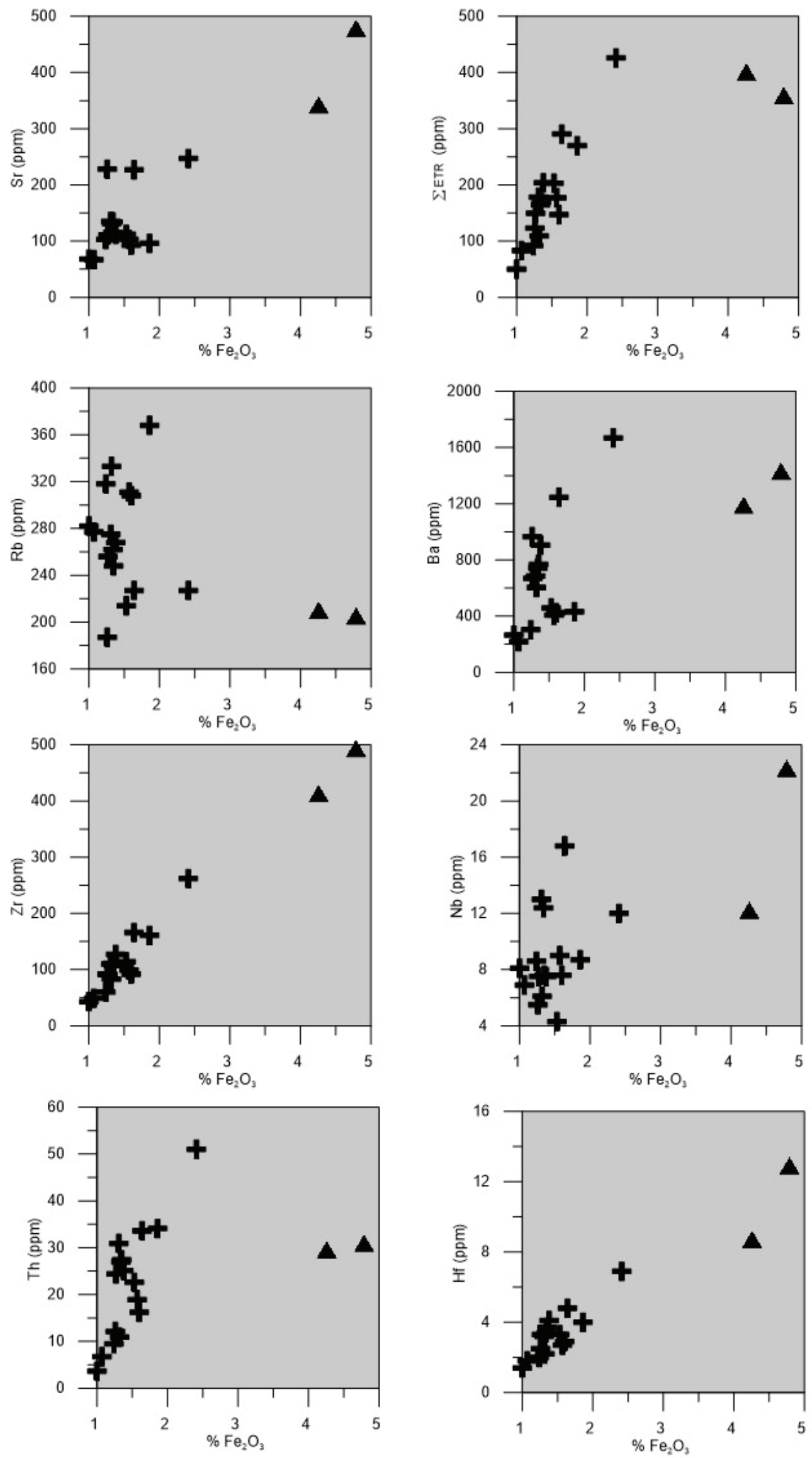

Figura 7. Diagramas de variação de alguns elementos traço para o granito de duas micas de Banabuiú (cruzes) e para o granodiorito biotítico de Novo Encanto (triângulos).

Figure 7. trace elemente variation diagrams of the Banabuiú two-mica granite (cross symbol) and Novo Encanto biotite granodiorite (triangle symbol). 
negativas de Eu pouco expressivas, considera-se possível que a reduzida amplitude das anomalias negativas de Eu no granodiorito de Novo Encanto esteja relacionada com a participação deste tipo de processos na sua petrogênese.

A participação de magmas básicos de origem mantélica na petrogênese de outros batólitos do Domínio Ceará Central também tem sido considerada em outras investigações. A presença de enclaves máficos no seio de rochas igneas dos Batólitos de Quixadá e Quixeramobim indica que a mistura de magmas ocorreu com a injeção de liquídos básicos na câmara

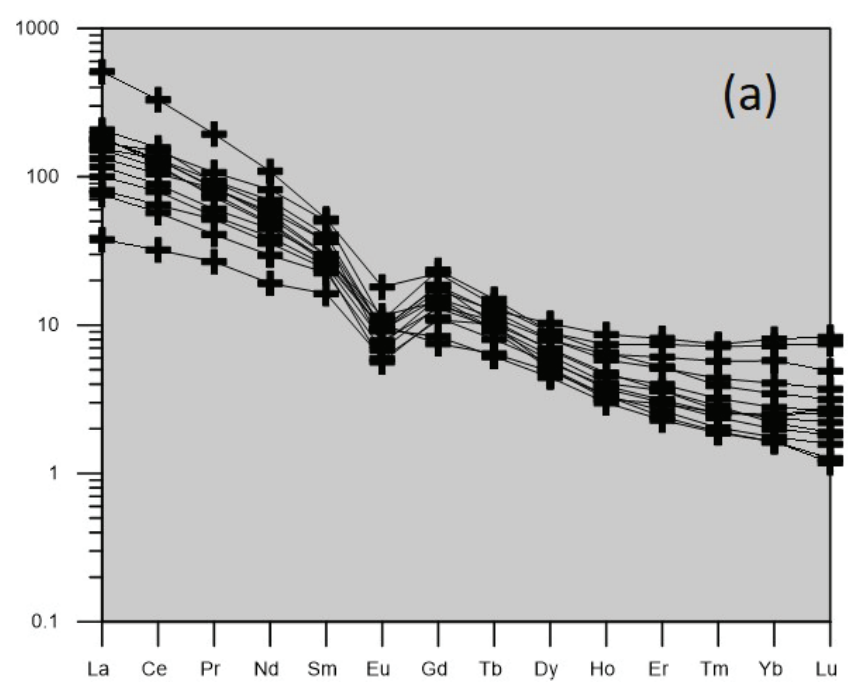

magmática. A assinatura geoquímica desses enclaves (teores elevados em Ba, Sr e ETR Leves; ausência de anomalias negativas em Eu; e baixo teor em ETR Pesadas) sugere que o magma máfico tenha uma origem mantélica (Almeida, 1995; Almeida \& Ulbrich, 2001). As datações $\mathrm{U}-\mathrm{Pb}$ e Pb-Pb, obtidas por Nogueira (2004), para os batólitos em questão forneceram idades de

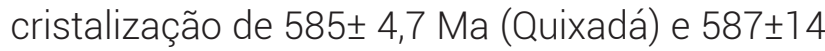
Ma (Quixeramobim), o que em conjunto com o Batólito de Banabuiú, classifica estes granitóides brasilianos como sin-colisionais.

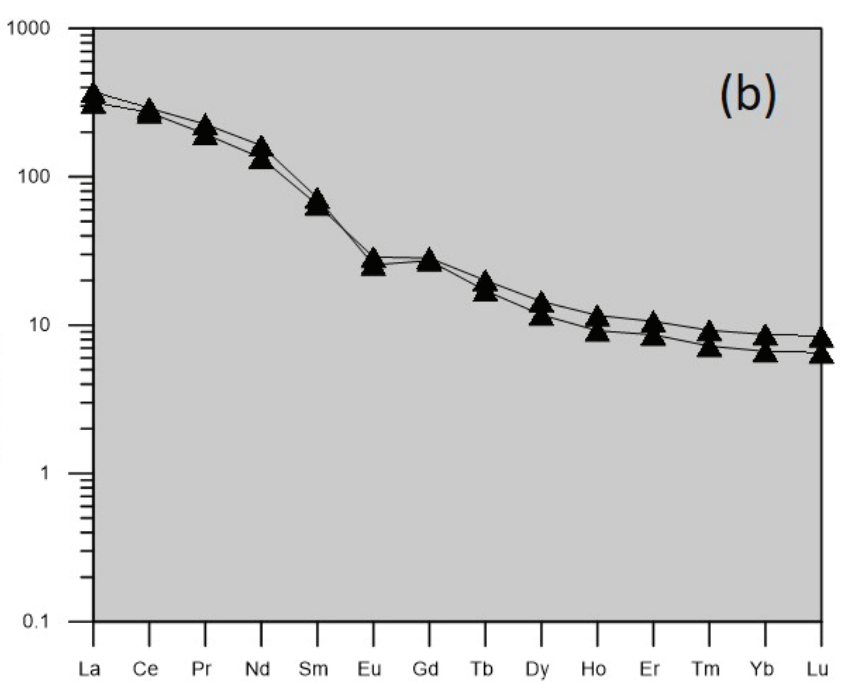

Figura 8. Padrões de ETR normalizados para o condrito de Evensen et al. (1978). A) granito de duas micas de Banabuiú; B) granodiorito biotítico de Novo Encanto.

Figure 8. REE normalized patterns to the Evensen et al. (1978) chondrite. A) Banabuiú two-mica granite; B) Novo Encanto biotite granodiorite.

\section{Conclusões}

No presente estudo, pretendeu-se descrever as relações entre o granito de duas micas de Banabuiú e um pequeno corpo de granodiorito biotítico que aflora no limite oriental do batólito granítico (Facies Novo Encanto). As características petrográficas e geoquímicas do granito de duas micas são compatíveis com uma derivação a partir da fusão parcial de protólitos metasedimentares supracrustais. Por outro lado, as características petrográficas e geoquímicas do granodiorito de Novo Encanto apontam para uma origem mais complexa, envolvendo a fusão de protólitos ígneos da crusta inferior ou a interação física e química entre magmas básicos de origem mantélica e magmas félsicos de anatexia crustal.
As relações de mixing e mingling observadas no contato entre as intrusões, indicam a coexistência e mistura parcial entre o magma granodiorítico e o magma granítico, sendo possível que o próprio granodiorito corresponda já a um termo híbrido. Contudo, para comprovar isso seria necessária uma coleta de amostras mais representativa, visando delimitar, de uma forma mais precisa, os processos petrogenéticos envolvidos na formação das zonas de mistura e do próprio granodiorito de Novo Encanto.

Em suma, as evidências encontradas levam a crer que durante os estágios finais da Orogenia Brasiliana, a instalação de magmas graníticos resultantes da fusão parcial, em grande escala, dos materiais da crusta superior, foi acompanhada pela intrusão de magmas intermediários de origem mais profunda (crusta 
inferior e/ou manto), tendo sido criadas condições para a ocorrência de fenómenos de mistura parcial de magmas ao nível da instalação.

A interação entre magmas de proveniência distinta poderá ter sido estimulada pela atuação de uma zona de cisalhamento profunda (neste caso a Zona de Cisalhamento de Orós), que teria favorecido a ascenção de magmas máficos de origem infracrustal/mantélica. Este mecanismo, que promove a ascenção de magmas básicos, também tem sido proposto para os processos de mistura de magmas que intervieram na petrogênese de batólitos da Provínicia Borborema, como os de Quixadá, Quixeramobim e Itaporanga (Mariano \& Sial, 1990; Almeida, 1995; Almeida \& Ulbrich, 2001).

Agradecimentos. Este trabalho foi financiado pela UID GeoBioTec (UID/GEO/04035/2013, FCT) e pelo projeto Metamorphic Evolution of the Granja Complex \& Metalogenetic Potential of the Ceará Central Pegmatites (SPU No: 11294909-6, FUNCAP, Brasil).

\section{Referências}

Almeida, A.R. 1995. Petrologia e aspectos tectônicos do Complexo Granítico QuixadaQuixeramobim, CE. São Paulo, 279p. Tese de Doutorado, Programa de Pós-Graduação em Mineralogia e Petrologia, Instituto de Geociências, Universidade de São Paulo.

Almeida, A.R. \& Ulbrich, H.H.G.J. 2001. O papel da mistura de magmas na gênese do magmatismo granítico cálcio-alcalino Quixeramobim-Ce. Revista de Geologia, 14:49-80.

Almeida, F.F.M., Brito Neves, B.B. \& Fuck, R.A. 1977. Províncias estruturais brasileiras. In: SIMPÓSIO DE GEOLOGIA DO NORDESTE, 8., 1977, Campina Grande, p. 363-391.

Almeida, F.F.M., Hasui, Y., Brito Neves, B.B. \& Fuck, R.A. 1981. Brazilian structural provinces: an introduction. Earth Science Reviews, 17: 1-29.

Arthaud, M.H. 2007. Evolução Neoproterozóica do Grupo Ceará (Domínio Ceará Central, NE Brasil): da sedimentação à colisão continental brasiliana. Brasília, 132 p. Tese de doutorado, Programa de Pós-graduação em Geologia,
Instituto de Geociências, Universidade de Brasilia.

Arthaud, M.H., Fuck, R.A., Dantas, E.L., Santos, T.J.S., Caby, R. \& Armstrong, R. 2015. The Neoproterozoic Ceará Group, Ceará Central domain, NE Brazil: depositional age and provenance of detrital material. New insights from U-Pb and Sm-Nd geochronology. Journal South American Earth Sciences, 58: 223-237.

Brito Neves, B.B. \& Cordani, U.G. 1991. Tectonic evolution of South America during the Late Proterozoic. Precambrian Research, 53: 2340.

Brito Neves, B.B., Santos, E.J. \& Van Schmus, W.R. 2000. Tectonic history of the Borborema Province, northeastern Brazil. In: Cordani, U; Milani, E.J., Thomaz Filho, A. \& Campos, D.A. (Eds). Tectonic Evolution of South America:

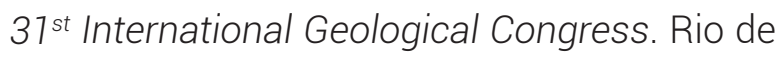
Janeiro, Brasil, p. 151-182.

Castro, A., Moreno-Ventas, I., de la Rosa, J.D. 1991. H-type (hybrid) granitoids: a proposed revision of the granite-type classification and nomenclature. Earth Science Reviews, 31: 237-253.

Chappell, B.W. \& White, A.J.R. 1974. Two contrasting granite types. Pacific Geology, 8:173-174.

Chappell, B.W. \& White, A.J.R. 1984. I- and S-type granites in the Lachlan Fold Belt, southeastern Australia. In: Keqin, X. \& Guangchi, T. (Eds). Geology of Granites and Their Metallogenic Relations. Beijing, Science Press, p. 87-101.

Chappell, B.W. \& White, A.J.R. 1992. I- and S-type granites in the Lachlan Fold Belt. Transactions of the Royal Society of Edinburgh: Earth Sciences, 83: 1-26.

CPRM-SBG. Serviço Geológico do Brasil. 2003. Mapa Geológico do Estado do Ceará, Fortaleza, escala 1:500.000.

Debon, F. \& Le Fort, P. 1983. A chemicalmineralogical classification of common plutonic rocks and associations. Transactions of the Royal Society of Edinburgh: Earth Sciences, 73(3): 135-149.

Debon, F. \& Le Fort, P. 1988. A Cationic Classification of Common Plutonic Rocks and Their Magmatic Associations: Principles, Method, Applications. Bulletin de Mineralogie, 
111: 493-510.

Donaire, T., Pascual, E., Pin, C. \& Duthou, J.L. 2005. Microgranular enclaves as evidence of rapid cooling in granitoid rocks: The case of the Los Pedroches granodiorite, Iberian Massif, Spain. Contributions to Mineralogy and Petrology, 149: 247-265.

Evensen, N. M., Hamilton, P. J \& O'nions, R. K. 1978. Rare-earth abundances in chondritic meteorites. Geochimica et Cosmochimica Acta, 42: 1199-1212.

Ferreira, V.P., Sial, A.N. \& Sá, E.F.J. 1998. Geochemical and isotopic signatures of Proterozoic granitoids in terranes of the Borborema structural province, northeastern Brazil. Journal of South American Earth Sciences, 11(5): 439-455.

Gill, R. 2010. Igneous rocks and processes, a practical guide. London, Wiley-Blackwell, 428 p.

La Roche, H., Leterrier, J., Grandclaude, P. \& Marchal, M. 1980. A classification of volcanic and plutonic rocks using R1-R2 diagram and major element analysis. Its relationships with current nomenclature. Chemical Geology, 29(1): 183-210.

Lima, M.N. 2014. Relações petrogenéticas entre o Complexo Gnáissico Migmatítico e o Granito de Banabuiú (NE do Brasil). Aveiro, 198p. Tese de Doutoramento, Programa Doutoral em Geociências, Universidade de Aveiro/ Universidade do Porto.

Lima, M.N., Azevedo, M.R., Nogueira Neto, J.A., Rosa, G.M. \& Cordani, U.G. 2009. Rb-Sr and $\mathrm{K}$-Ar ages for pegmatites from the Banabuiú region, Borborema Province, Brazil. Estudos Geológicos, 19: 188-192.

Lima, M.N., Nogueira Neto, J.A., Azevedo, M.R. \& Valle Aguado, B. 2010. Geología y geocronología U-Pb del granito de Banabuiú, Noroeste Ceará, Brasil. Estudios Geológicos, 66(1): 35-44

Mariano, G. 1989. Magma mixing origin of Potassic Calk-alkaline pluton: the Itaporanga Batholith, state of Paraiba, Northeastern Brazil. Athens, 180p. PhD thesis, Undergraduate
Programme in Geology, University of Georgia.

Mariano, G. \& Sial, A.N. 1988. Evidence of magma mixing in the Itaporanga batholith, Northeastern Brazil. Rendiconti della Società Italiana di Mineralogia e Petrologia, 43(2): 555568.

Mariano, G. \& Sial, A.N. 1990. Coexistence and mixing of magmas in the Late Precambrian Itaporanga batholith, state of Paraíba, northeast Brazil. Revista Brasileira de Geociências, 20: 101-110.

Martins, F. 2014. Fusão crustal e metamorfismo de alto grau no Domínio Ceará Central (NE do Brasil). Aveiro, 115p. Dissertação de Mestrado, Mestrado em Geomateriais e Recursos Geológicos, Universidade de Aveiro, Portugal. Neves, S.P. \& Mariano, G. 1997. High-K CalcAlkalic Plutons in Northeast Brazil: Origin of the Biotite Diorite/Quartz Monzonite to Granite Association and Implications for the Evolution of the Borborema Province. International Geology Review, 39(7): 621-638.

Nogueira, J.F. 2004. Estrutura, Geocronologia e Alojamento dos Batólitos de Quixadá, Quixeramobim e Senador Pompeu - Ceará Central. Rio Claro, São Paulo, 123. Tese de doutorado, Programa de Pós-Graduação em Geociências e Meio Ambiente, Instituto de Geociências e Ciências Exatas, Universidade Estadual Paulista.

Patiño Douce, A.E. \& McCarthy, T. 1998. Melting of crustal rocks during continental collision and subduction. In: Hacker, B.R. \& Liou, J.G. (eds). When Continents Collide: Geodynamics and Geochemistry of Ultrahigh-Pressure Rocks. Dordrecht, Netherlands, Kluwer Academic Publishers, p. 27-55.

Van Schmus, W. R., Brito Neves, B. B., Hackspacher, P. \& Babinski, M. 1995. U/Pb and $\mathrm{Sm} / \mathrm{Nd}$ geochronologic studies of the eastern Borborema Province, Northeastern Brazil: Initial conclusions. Journal of South America Earth Sciences, 8: 267-288.

Vernon, R. H. 2008. A practical guide to rock microstructure. Cambridge, Cambridge University Press, 594 p. 